\title{
The Historical Comparative Analysis of the Development and Transformation of Lei Yue Mun and Cha Kwo Ling with Their Tin Hau Temples
}

\section{Chung Fun Steven Hung}

The Education University of Hong Kong

\begin{abstract}
Today, Lei Yue Mun and Cha Kwo Ling are still the nearby urban areas and the urban fringe areas respectively. They are squatter areas and both suffer from environmental hygiene problems and lack proper management. The historical development of Cha Kwo Ling exerted superiority in the long-term. If compared to Lei Yue Mun, its economic, societal and cultural development performed better. Therefore, the administrative-governed centers, namely, the 'Communal Office of the Four Hills' and the 'Communal School of the Four Hills' were developed in Cha Kwo Ling. After the Second World War, Cha Kwo Ling had some nearby local developments, for example, there were built several oil depots and quarry sites next to it. This made Cha Kwo Ling become even more prosperous. This statement can be strengthened by the massive and spectacular occasion of the 'Tin Hau Festival.' This grand event is the most popular and large-scale in the urban area. Coincidentally, Lei Yue Mun underwent certain transformations in the 1960s. It became a tourist hot spot for eating seafood. Up to now it is internationally famous which helps maintaining its prosperity. In contrast, the economic development of Cha Kwo Ling started to deteriorate because of the urban developments. But there is a sharp difference if residents' sentiments are taken into account. With the successful economic development in Lei Yue Mun, its residents become more cold-blooded and snobbish. This is a total opposite reflection of the social relationship in Cha Kwo Ling - its residents are warm-blooded, they are passionate and are always ready to provide mutual help and care. The situation in Lei Yue Mun is quite different.
\end{abstract}

Social Evolution \& History, Vol. 19 No. 1, March 2020 147-169

(C) 2020 'Uchitel' Publishing House

DOI: $10.30884 / \mathrm{seh} / 2020.01 .08$ 


\section{INTRODUCTION}

The essential understanding of the local history is different from the general Hong Kong history. The researchers can also base on the analysis of local history to develop a known and specialized Hong Kong history. It challenges the local historical mainstream discourse, or the general narration. The Kwun Tong district on the east side of Kowloon Peninsula (the name stemming from nine dragons) is situated close to the Victoria Harbor. It is the first generation of Hong Kong's satellite cities which later developed to become a place for commercial, industrial and residential use. The focus of this paper is to elaborate historical comparison of the development and transformation of two areas in Kwan Tong. We hope this will contribute to understanding and interpretation of different paths of social change in Hong Kong context. The study compares different changes (e.g., social, geographical, historical and economic ones) in Lei Yue Mun and Cha Kwo Ling. It also addresses various community building processes and explains the issues of flourishing and deterioration in order to provide a thorough historical picture of their social developments. These are good examples illustrating the uniqueness of Hong Kong.

\section{THE BACKGROUND OF LEI YUE MUN AND CHA KWO LING WITHIN HONG KONG HISTORY}

Hong Kong was a sparsely populated corner on the coastal frontier of China. It has a long history of development and once was occupied by immigrants whose only a small minority worked in the agricultural sector. The rest had to rely on salt, pearl and fishery trades to make their living (Liu 1997: 10-15). Before it was colonized by Great Britain, the Punti, Hakka, Tanka and Hokkien people had migrated to and stayed in Hong Kong for many years. The rural society was tightly bound together by patrilineal relation and religion. The Chinese who were building Hong Kong followed the tradition of rural villages and established their new communities around the temples which they set up. The temples had essentially become the center where people worshipped, assembled, sought arbitration and mutual support (Luk 2005: 43). By 1860, Britain gained control over the Kowloon Peninsula and the population increased to over 100 thousand people, surrounded with 30 thousand (30 per cent) floating people. The economy was closely connected with commercial activities, dominated by shipping, banking and merchant businesses. In order to meet the needs of Chinese merchants and resi- 
dents, there was an increasing diversification of services, with different retail outlets being opened during that period.

With the leasing of the New Territories to Britain and the transformation of China, there were some industrial expansions, in particular, in the early twentieth century there appeared sugar refining, cement and ice factories in the foreign sector as well as smaller-scale local workshop manufactures. However, its history was generally ignored and Hong Kong is interpreted as merely an entrepot. Meantime, the Chinese in Hong Kong gained advantages for the global trading. As Hong Kong developed, its population increased from 300 thousand in 1900 to 840 thousand in 1931. The prospering business and industry had become a symbol of successful capitalism. 'The entrepreneurial spirit, resourcefulness and business acumen of the local Chinese that made prewar Hong Kong what it was were quickly at work' (Tsang 2004: 161). So the Hong Kong goods were exported throughout the world.

Hong Kong often appeared at the receiving end of mass waves of migrants from China (Carroll 2007: 3). After the Second World War, the skills and capital were again brought to Hong Kong and this time by the refugees from Shanghai. Squatters spread in a ramshackle rash up hills, vulnerable to rainstorms and prone to dangerous fires. However, the British Hong Kong government launched the (re-)settlement programme by providing public housing for the poor. A vast pool of cheap labor contributed to the flourishing of economy and performed a miracle. Hong Kong was quite stable except for the periods of the riots which occurred in 1956, 1966 and 1967. At this stage Hong Kong also played an important role for the People's Republic of China. It minimized the impact of the Cold War by ignoring it (Tsang 2004: 158) and concentrating on its own development. Enjoying unprecedented growth, Hong Kong transformed from a territory of entrepôt trade into one of the major industrial and manufacturing centers, and then into the international financial centre and a fast-growing metropolitan country. This was the golden era of Hong Kong. Benefiting from prospering, the living standards of Hong Kong residents improved very much. In the New Territories, many abandoned rice fields became construction sites and eventually high-rise towers. Hong Kong is an international business, trade and financial hub whose success is based on its crucial economic policy in making of laissez-faire economic system. Hong Kong has developed into a modern, vibrant and cosmopolitan services economy, underpinning the role of the city as a global business plat- 
form (Harbour and Hills... N. d.). However, this should not be considered as the only unique development in Hong Kong since in addition to the above described, many other local changes have occurred that people should be aware of.

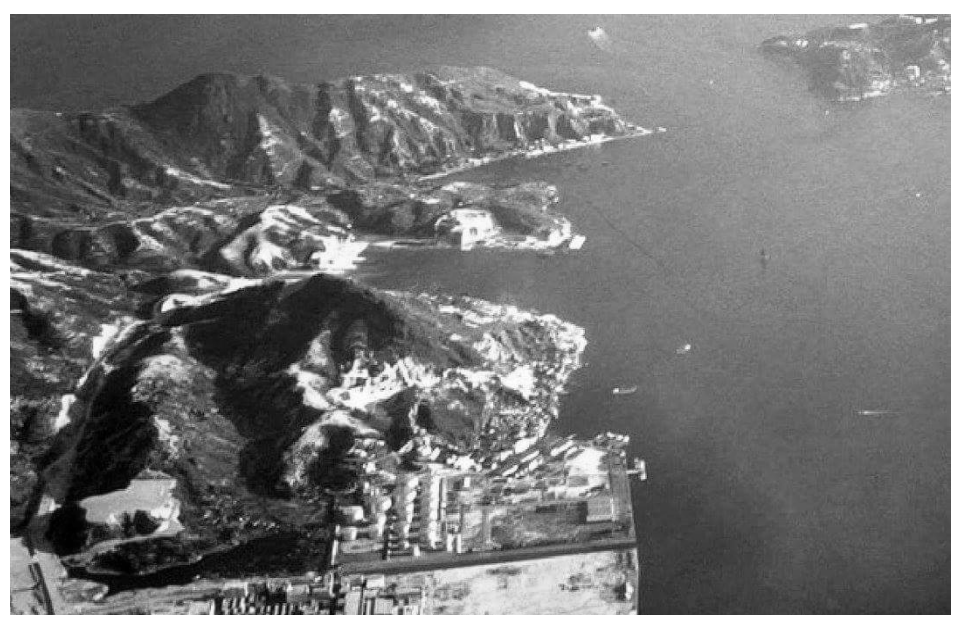

Fig. 1. The central part is Cha Kwo Ling surrounded by the oil depot and kaolin mining, the upper coastal is Lei Yue Mun in 1960 and the lower left hand corner is Sai Tso Wan Source: Author's collection

Lei Yue Mun (Lyemun, Lymoon Pass, Lye Moon Passage or Lyee-moon Passage 鯉魚門, got its name from the estuary of salt river in old China) and it is one of the straits in Hong Kong. It is the east gate of the Victoria Harbor separating the north-eastern part of Hong Kong Island and the south-eastern coastal areas of the Kowloon Peninsula. Cha Kwo Ling is situated on the eastern shore of Kowloon Bay (Chan 1957: 3) in the eastern part of Kowloon, and north westward of Lei Yue Mun. The distance is around 1.4 kilometer. Behind the hill there is Sai Tso Wan area (see Fig. 1), and on the north-western side there is Ngau Tau Kok area. The residents used to earn their living from mining and agricultural activities. Since the nineteenth century, the 'Four Hills' in the east Kowloon - Lei Yue Mun, Cha Kwo Ling, Sai Tso Wan and Ngau Tau Kok (Lee 2010: 4; Chan and Lee 2012: 32) - were called 'Four Hills of Kowloon'. Later, they started to develop into villages and build up establishments. The two territories (Lei Yue Mun and Cha Kwo Ling) were quite isolated until the development of Kwun Tong district. 
There are three different beliefs about how 'Lei Yue Mun' got its name. First, in the old days, there were two fish ponds that were famous for feeding cyprinus carpios (鯉魚) in the village and the shape and the laid position were very similar to the eyes of cyprinus carpio. The second explanation is that at that period of time the water channels of Kowloon Bay and Lei Yue Mun were built together and they looked like a fat and big cyprinus carpio. The narrow gate (of the water channel) was described as the fish's mouth. Since the Kowloon Bay has a fishtail rock, therefore, it was named as Lei Yue Mun. And the third idea is the following: there are many stones along the Lei Yue Mun water channel so when the waves hit the stones, it seems the $c y$ prinus carpios are leaping through the water. In addition, most reefs have the shape of cyprinus carpios.

Cha Kwo Ling (茶果嶺) is situated between Laguna City and Yau Tong. There are two different ideas about how 'Cha Kwo Ling' got its name. One explanation is that there is a hill behind Cha Kwo Ling village. On the top of the hill, there was a large area of exposed granite rocks without covering plants (Chan 1957: 4). Every time when fishermen went out to catch fish, they turned around and looked at the hill. It was semi-circular and its shape resembled Macaranga tanarius. Another explanation is that most of Cha Kwo Ling residents are Hakka who love to make and eat cha kwo, a traditional Hakka snack. They also plant many Macaranga tanarius trees at the back of the village. The (tree) leaves are used for wrapping cha kwo as they are prepared for steaming.

At that time, 'the four hills of Kowloon' were all Hakka villages, whose residents were mainly involved in mining quarries and granites (Lee 2010: 4). These were one of the most important natural resources in Hong Kong which were used in construction industry. In the early nineteenth century, some residents of the Lei Yue Mun village worked in masonry (stonebreaker), while others were engaged in agriculture. In the course of the early historical development of Hong Kong, it was maritime-based (Chan and Lee 2012: 35). Initially, people in Hong Kong sustained themselves via fishing. Later, they got involved in overseas trade. Therefore, the ideas of 'burning incense' and 'worship' (ritalism) are closely related to the maritime climate. In Hong Kong the trade would emerge along the coastal areas in the South China region, so the fishermen from Fujian and Guangdong would settle in those areas. Since the Song dynasty, the fishermen believed and worshiped 'Tin Hau' (Empress of Heaven, 天后). Therefore, it was common to found Tin Hau Temple if there was a fishermen's settlement. 
Currently, the total number of Tin Hau Temples in Hong Kong should be more than a hundred. Most of them are named 'Tin Hau Temple' or 'Tin Hau Kung'. Thus, the worship of 'Tin Hau' has a very long history.

The Tin Hau Temples in Lei Yue Mun and Cha Kwo Ling witnessed the development of Hong Kong history, which started from a primary industry - quarry mining and agriculture, then developed to fishing business, finally, it transformed into current international business center. The beliefs, worship, and traditions of Tin Hau Temples are also passed from one generation to another. The relationship between Lei Yue Mun and Cha Kwo Ling is very close. They both have Tin Hau Temples although they were not merely fishing villages and originally started as quarry-mining areas (Hung 2015: 20).

\section{THE METHOD OF HISTORICAL AND COMPARATIVE STUDY}

In Hong Kong many religions coexist which nevertheless had similar developmental paths. Lei Yue Mun and Cha Kwo Ling are two nearby places where 'Tin Hau' was worshipped during the Late Ching dynasty. After the Second World War, these two territories had different paths of development due to urbanization. In the present article we apply the comparative method to study the relevance of social changes in the two areas for Hong Kong history in general. The Tin Hau cult was the most popular Chinese ritual in the region. The comparative historical study examines the development and transformations of these two places in order to give appropriate explanation of relevance to the present day. The ritual activities of Tin Hau Temples explain the communal organization and neighborhood of these two areas. For adopting a normative perspective, comparisons have served as a tool for developing classifications of social phenomena and for establishing whether shared phenomena can be explained by the same reasons. The comparative approach to the study of changing communities in these two areas may reveal the substantial changes of Hong Kong development.

\section{THE HISTORICAL TRANSFORMATION AND ORIGIN OF 'TIN HAU' AND TWO TIN HAU TEMPLES (IN LEI YUE MUN AND CHA KWO LING)}

'Tin Hau', also called 'Mazu' (馬祖), was a Fujianese girl and her original name was 'Lin Moniang' (林默娘). Lin was born a talent person and she possessed wide medical and astronomical knowledge. 
However, she was also a witch who saved people drowning in the sea. After her death, she was still appreciated by officials of different dynasties and emperors and hence she was rewarded. She was promoted to Imperial concubine. Later, she became to be revered as Tin Hau. People respect and worship Tin Hau because she protects them at sea, and guarantees their marine safety. In the Northern Song dynasty, people started to build temples to commemorate and worship her. They also gave her another name - 'Tongxian Goddess' (通賢神女, the Goddess of proficient in virtues).

\section{The Origin of the Tin Hau Temple in Lei Yue Mun}

The Tin Hau Temple in Lei Yue Mun was built by the pirate Cheng Lin-Cheong in the eighteenth year of the Qianlong reign period (in $1753 \mathrm{AD}$ ). It is located at the end of the village. Facing the opposite side of the Lei Yue Mun temple, there is the Shau Kei Wan neighborhood. It was constructed along the curbs in the coastal area. At that time, the pirates occupied Lei Yue Mun and considered Devil's Peak as looting base. So Lei Yue Mun had important strategic importance at that time.

Cheng Lin-Cheong's grandfather was unable to catch up with the troop when they were moving to Taiwan in 1661. Therefore, he continued his pirate life, moving south from Fujian Zhangzhou to Lei Yue Mun. The Tin Hau Temple in Lei Yue Mun served as an outpost for the pirate Cheng and helped to prevent invasion from government troops (Lee 2010: 12) while the back of the hill was used for food storage. After the death of Cheng Lin-Cheong, his son 'Cheng I' inherited the power and authority. Later, it was his wife 'Cheng I Sao' who took over the power. Together with her 'right-hand man' Cheung Po-Tsai he expanded their military base along the coastal areas which reached far to Cheung Chau island (southwest of Hong Kong). Once Cheung PoTsai surrendered to the Manchurian Qing, the Admiral of the Imperial Navy of Guangdong 'Lee Zhun' and the Viceroy of Guangdong and Guangxi Provinces ‘Zhang Mingqi' set up 'Yamen' (衙門, government office), or it may be referred as the administrative office of a local government in Kowloon Walled City. By that time, the villages of Ngau Tau Kok, Sai Tso Wan, Cha Kwo Ling and Lei Yue Mun were collectively referred as 'Four Hills'. The old site of Tin Hau Temple in Cha Kwo Ling is connected with the origin of the Tin Hau Temple in Sai Tso Wan. When the Tin Hau Temple in Lei Yue Mun was the area occupied by the pirate Cheng Lin-Cheong, this did not actual- 
ly correspond to the fishermen's belief that they went to Tin Hau to seek for marine safety and protection.

In 1953, there appeared a legend about Lei Yue Mun, Goddess of the Sea - as she made her presence or power perceived. It was said that she appeared in the dream of the temple attendant, who was responsible for managing incense and religious service, and requested to re-construct the Tin Hau Temple. By 1953, the Tin Hau Temple in Lei Yue Mun had been long-neglected and was in a state of disrepair. Therefore, it was re-constructed and later, in 1986, underwent the second reconstruction. At that time, the village mayor Luo Ping trusted the temple attendant's sayings. He believed the Goddess of the Sea really made her presence perceived. In 1953, on the fifth day of April of the Chinese Lunar calendar, he captured the Goddess of the Sea's photo. The residents of Lei Yue Mun continuously believed in this legend, and passed it down through generations. In the same year it was discovered during the reconstruction of the temple that two hundred years ago (in the year 1753) Cheng Lin-Cheong actually built it with the monument. The following words were engraved on this monument: 'Tin Hau Kung, (the temple) is constructed by me. My grandchildren would be responsible for managing this in the future. Written in spring, the eighteenth year of the Qianlong reign period.' This monument was discovered two hundred years later and scholars are still unable to verify its authenticity. Thus, regarding the origin of the Tin Hau Temple in Lei Yue Mun, further investigation is needed. During the year of temple re-construction, people would add different stone carvings around it like, for example, '海角潮音' (tidal sound at sea cape), which was inscribed by Chen Ben-Zhao, the headmaster of the Tai Po Rural Training College (RTC) during the pre-war period and written in 1953.

\section{The Origin of the Tin Hau Temple in Cha Kwo Ling}

The old site of the Tin Hau Temple in Cha Kwo Ling is located at the southern side of Sai Tso Wan area in Kwun Tong District. It was developed by the government officials during the Daoguang reign in the Qing dynasty, and was reconstructed in the seventeenth year of Guangxu reign (year 1891). Its old name was 'Sai Tso Wan Tin Hau Temple' (Hung 2017: 97). According to the information provided by the Chinese Temples Committee, the old site of Tin Hau Temple in Sai Tso Wan was destroyed by hurricane in 1911-1912. It was until 1941 that local people were collecting donations for its reconstruction.

In 1947, the areas around the Sai Tso Wan and its Tin Hau Temple were chosen for the construction of the Asiatic oil depot by recla- 
mation. It was further acquired by Shell oil company so the temple was demolished. In order to respond to the residents' appeal, the local government reconstructed another Tin Hau Temple in Cha Kwo Ling. Currently, in the Tin Hau Temple in Cha Kwo Ling the stone door frames are the same as the ones used in original temple (Hung 2017: 98). The (construction) materials were extracted from granite in the quarry site in Cha Kwo Ling. Once the 'Shell' company constructed Asiatic petroleum storage in Sai Tso Wan, it then became the base for petrol storage of in the Far East area.

\section{THE HISTORICAL TRANSFORMATION OF THE TWO TERRITORIES}

In 1863, the French Catholic Church needed stones to build the church to facilitate its development for evangelizing. Therefore, people were engaged in quarry-mining in the hills of Ngau Tau Kok in the Kowloon Peninsula, and also around the nearby hills in Cha Kwo Ling. The thing is that all the construction materials for the "Cathedral of the Sacred Heart of Jesus' located in Yide Road, Guangzhou, were extracted from the quarry site in Cha Kwo Ling. This building, whose construction was completed in 1869 , is also called 'Stone House' because it was fully made of granite. This is an example illustrating quarry-mining in Cha Kwo Ling which started in the nineteenth century. The New Territories were leased to Britain for 99 years from 1898 , and the two places were subject to British rule from that time onwards.

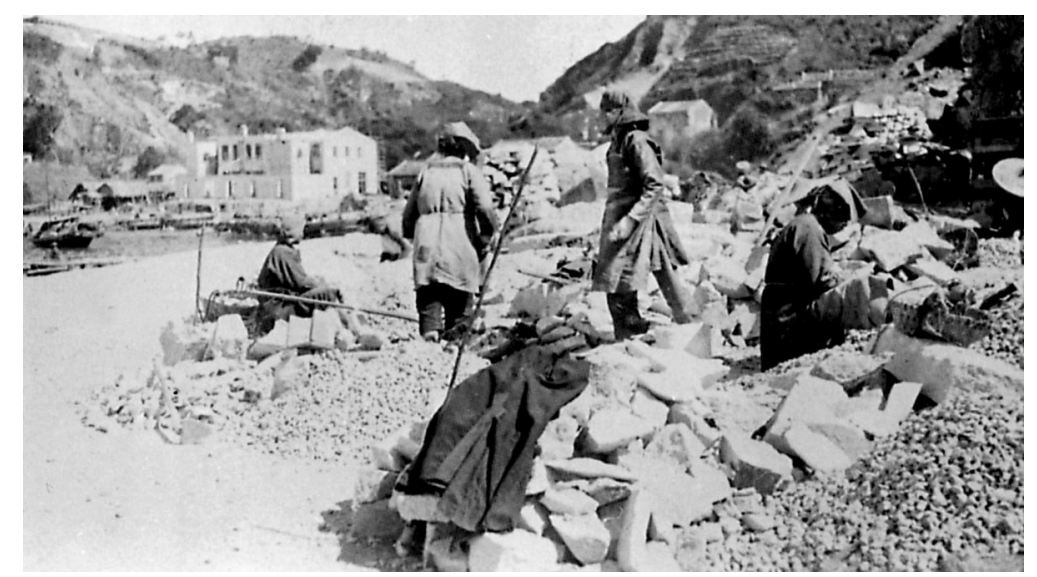

Fig. 2. Quarry mining at Lei Yue Mun in the 1930s Source: author's collection 
In 1918, the quarry site area of Lei Yue Mun was measuring 26.44 acres, while the one in Cha Kwo Ling was 24.56 acres. Both places relied on quarry-mining as the source of economic income. After the Second World War the residents of Cha Kwo Ling came to the nearby Anderson Quarry Site for quarry-mining. In the 1920s kaolin mining started to develop. They did not seem to be affected by the strikes in the 1920s (Chan 1957: 10). The 1967 Hong Kong Riots caused some changes in the post-war quarrying activity. Some smallscale stone factories were closed down because they were not allowed using explosives in quarrying and no mining license was issued. The quarry site in Cha Kwo Ling was operated by Anderson Company, and it underwent large-scale mining. In Lei Yue Mun, the villagers would go to the Lei Yue Mun Quarry Site for mining (see Fig. 2) since the village was also heavily dependent on quarry-mining. Originally there were no fishermen living there. There are different sayings about the Tin Hau Temple in Lei Yue Mun and the history of Tin Hau. Up to now, the story is still controversial.

According to demographic data, in 1911 there were 255 residents in Lei Yue Mun and 211 persons - in Cha Kwo Ling. This proves that these two villages had existed for a long time and could not be generally referred as 'remote' and 'under-developed'. Another point is that quarrying industry was one of the sources of government tax revenues in Hong Kong. The statistics was just a reflection of the residing population and it did not illustrate the number of people working in the quarrying industry. Both Cha Kwo Ling and Lei Yue Mun relied heavily on quarry-mining, but no later than in 1928, people in Cha Kwo Ling discovered the production of kaolin (see Fig. 1). The kaolin production is hundred times more profitable than that of granite $(\mathrm{Ng}$ 1963: iv). People not only mined granites in the quarry sites but also kaolin hereafter. This made Cha Kwo Ling more prosperous.

The four villages (Ngau Tau Kok, Cha Kwo Ling, Sai Tso Wan and Lei Yue Mun) have a common feature - quarrying was their mainstream economy. They formed an alliance which also facilitated their maintenance. They were called 'Four Hills'. Every village-hill could choose its own representative. The official name was 'the headman of the Four Hills'. The person was responsible for managing all local affairs and assisting the Qing government in collecting taxes from quarry companies (Hung 2017: 97). Later, due to the production of kaolin in Cha Kwo Ling, the Cha Kwo Ling village became prosperous. To manage the village alliance, the headman of the Four Hills set up a 'communal office of the Four Hills' in Cha Kwo Ling. Since the residents of the Kowloon Four Hills did not have ancestral halls, the Tin 
Hau Temple in Sai Tso Wan (today's Laguna City) became the focal point linking these scattered villages during the pre-war period. It was also the place to handle affairs of the Kowloon four hills, and served as a platform for the headman of four hills to discuss local affairs (Lee 2010: 5; Chan and Lee 2012: 36).

The inhabitants of both Cha Kwo Ling and Lei Yue Mun were engaged in quarry-mining. The historical development of Cha Kwo Ling was gradually changing - from economic prosperity to decline while the case of Lei Yue Mun was just the opposite. The Tin Hau Temples of the two places also witnessed the historical developments. Quarrying was the mainstream economic sphere (business) in Cha Kwo Ling until 1928 when the production of kaolin was discovered. Since the price of kaolin is higher, the incomes of Cha Kwo Ling residents' would increase. But unfortunately, the geographical location of Cha Kwo Ling was quite remote and inconvenient; besides, there was inadequate transportation facility support in the village. Its residents had to rely heavily on support from outside (e.g., in materials provision from Hong Kong Island) (Hung 2015: 25). This was especially true should they need medical services. During that period, it was only the hand-operated cable ferry that travelled between Cha Kwo Ling and Hong Kong Island. The emerging later 'motor/electric boats' operated between Cha Kwo Ling and Shau Kei Wan areas (Ibid: 24). The lack of transport accessibility was a problem; therefore, the situation gradually deteriorated in economic terms.

The Japanese invasion of Hong Kong in December 1941 caused a sharp decrease in the number of residents in Cha Kwo Ling and it was only after 1945 that the residents would come back to re-start their jobs in Cha Kwo Ling. Additionally, the Chinese Civil War forced many Mainland migrants to come to Hong Kong which resulted in population increase. The residents opened different shops, restaurants, pharmacies, maintenance shops, and factories. All trades and professions became very prosperous in Cha Kwo Ling.

On the other hand, in 1947, the British-owned 'Asiatic Petroleum Company' constructed a new oil depot in Sai Tso Wan. Cha Kwo Ling then became the base for the storage of petrol in the Far East area (Hung 2015: 22). Thus, the job market in Cha Kwo Ling thrived. The employees working for the oil company moved to reside in Cha Kwo Ling in order to facilitate their movement from and to office. Additionally, at that time the housing problem was quite serious in Hong Kong so the inadequate housing made many settlers build squatters. This made Cha Kwo Ling's trades and professionals become even more prosperous in the 1950s. Along the Cha Kwo Ling Main Street, 
more than hundred shops worked. Cha Kwo Ling at that period was the local market for people buying daily supplies. This provides evidence of Cha Kwo Ling's prosperity in the past (Hung 2015: 27).

There were observed two more changes in Cha Kwo Ling in 1947. First, the Tin Hau Temple underwent reconstruction. Second, the 'Communal office of the Four Hills' was re-established. It was followed by the establishment of the 'Communal School of the Four Hills' in 1952. Being one of the 'Kowloon Four Hills', Cha Kwo Ling increased its significance in comparison to other three villages. In 1956, the villagers established a social club for themselves. The former name was 'Cha Kwo Ling village office'. Locally, Cha Kwo Ling had oil depot, kaolin mining sites and stone quarry sites (see Fig. 1). There were also built several factories. The labor productivity was quite high. The nearby Tanka Shing (the city of Tanka's people) became a gathering place for fishermen hence it provides anchorage for their boats. There were also opened many seafood restaurants and wholesale companies. Tanka Shing became a concentrated place for goods (e.g., sea food) within the district. The Cha Kwo Ling 'Hop Yee Tong Association' had its own dragon boat team. They were a winning team and almost never lost. The other name of it was 'the dragon king' and the fishermen liked its activities very much.

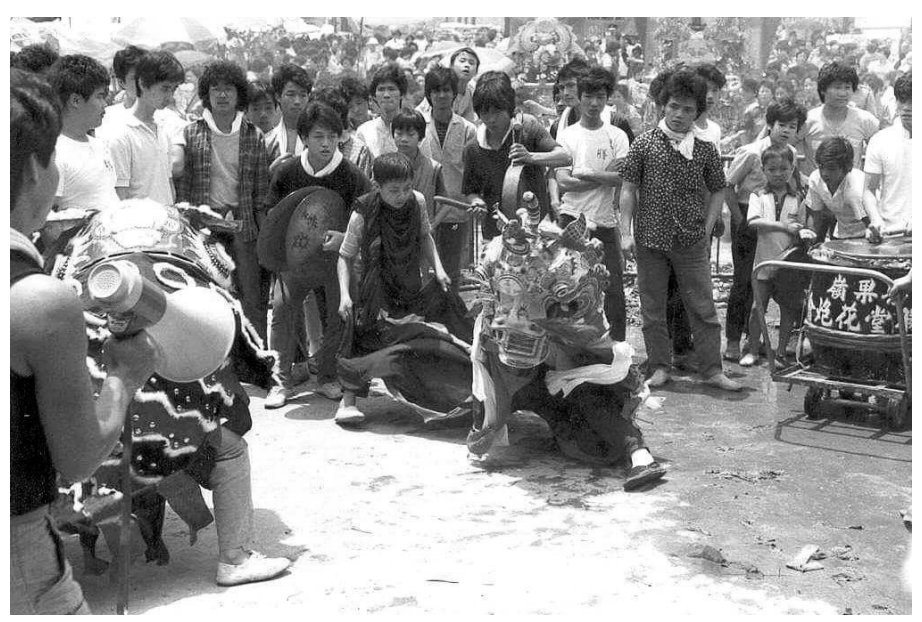

Fig. 3. The Tin Hau Festival at Cha Kwo Ling in the 1970s Source: author's collection

At that time, the government had not yet built Kwun Tong Industrial District. The reclamation work had just started. Basically in the 
1950 s it was a remote area without any factories. Because of its remoteness, quite a few people worked there. There were 1,000 employees in Cha Kwo Ling's industries.

The Cha Kwo Ling Rural Committee and Kaifong Association were responsible for managing the Tin Hau Temple. Later, due to the confusion in accounting management, the management rights were taken over by the Chinese Temples Committee. Tin Hau Festival was the most popular local activity. Many dignitaries would be willing to attend the ribbon-cutting ceremony thus adding more fun to the event (see Fig. 4). In the early 1970s, Zhang Xwen became the director of the Tin Hau Temple. But unfortunately, he had failed to provide a qualitative management and operation and also had problems with fiscal management. Thus, the management of the temple was transferred to the Chinese Temples Management Committee. This was different from Lei Yue Mun Tin Hau Temple, which was always managed by the villagers and residents. The transfer of management of the Tin Hau Temple did not exert any negative effect, so the Tin Hau Festival in Cha Kwo Ling remained very influential (see Fig. 4).

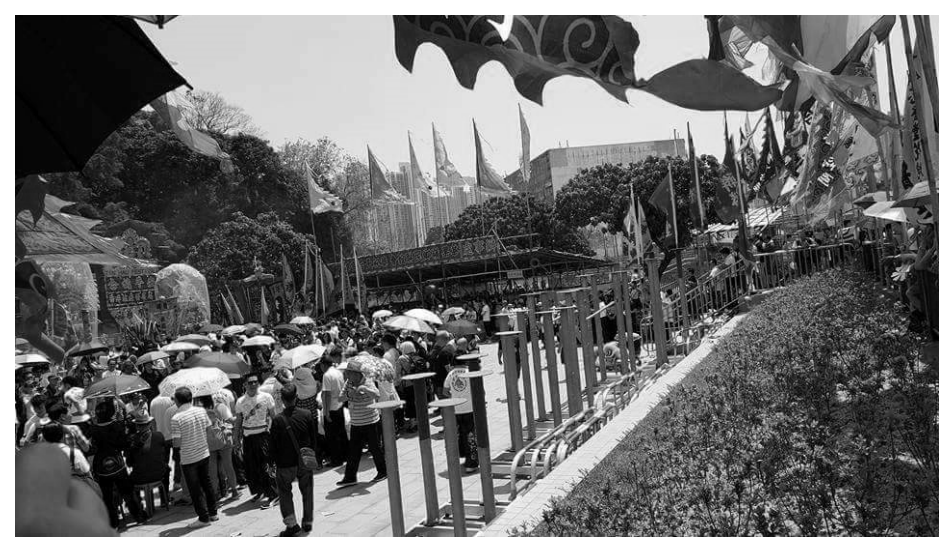

Fig. 4. The Tin Hau Festival in Cha Kwo Ling in 2015

Source: author's photo

With the development and changes in the region, the development of houses and squatters around Cha Kwo Ling slowly moved to a maturity stage. Its nearby area also underwent industrial transformation. In 1989, the Hong Kong residents started to move to Lam Tin Laguna City Phase One (residential buildings). Due to its developed infrastructure (e.g., well-equipped facilities and convenient transportation 
system) more and more people were attracted to settle in this area. On the contrary, the residents of Cha Kwo Ling squatters continued to suffer from poor living standards. The government made several attempts to construct a civic playground between Cha Kwo Ling and Yau Tong in order to get rid of squatters. Still the final decision had not been made so Cha Kwo Ling's development remained stagnant and many people moved out of the area. The same year Lam Tin Laguna City completed its development with all residential buildings being constructed. Shell Oil Company had to move from away Cha Kwo Ling since more and more residential buildings were constructed. The labors left. The nearby Eastern Harbor Crossing was open for traffic too (Kwok, Sun, and Wong 1987: 5-8). This led to a decline of the quarrying industry. All quarry sites stopped their operations. All these led to a decrease in Cha Kwo Ling's attractiveness. From that period until now there is only a minority of residents living in Cha Kwo Ling, most of them are new immigrants. The place is unable to withstand society's transformations and challenges. Now, Cha Kwo Ling is a silent, unknown village and is gradually being forgotten by others (Hung 2015: 28-29).

But, the tradition of Cha Kwo Ling Tin Hau Festival still survives. There is a close linkage between Cha Kwo Ling Tin Hau Temple and the origin of Tin Hau worship. Tanka Shing was a place close to Cha Kwo Ling. It used to be an inhabited place for fishermen in the past. As the seafood wholesale centers already existed in Cha Kwo Ling, the local fishermen valued much the development of Tin Hau Festival. Every year, the celebration of Tin Hau Festival in Cha Kwo Ling is grandiose, extensive and incomparable with other local events in the region (Hung 2015: 29-31). There is also a sharp contrast when people compare it with the Tin Hau Festival in Lei Yue Mun - the latter definitely proved to be inferior. The Tin Hau Festival in Cha Kwo Ling is held on the $23^{\text {rd }}$ of March of the Chinese Lunar calendar. The former inhabitants also come back to Cha Kwo Ling to participate in this annual grand event. Apart from the above, Cha Kwo Ling has the 'Hop Yee Tong' dragon boat team. They have taken part in many dragon boat competitions and always win, hence having a good reputation 'dragon king' (Ibid.: 28). All these serve as evidences that the Tin Hau Festival in Cha Kwo Ling is still of scale. Additionally, the local fishermen traditionally put a heavy emphasis on Tin Hau Festival. This became the impetus for a successful preservation of history to this day. All the above-described issues match the historical 
narration on the relationships between fishermen/fishing industry and Tin Hau Festival/Tin Hau Temple.

While the economic development in Lei Yue Mun changed from quarry-mining to the current seafood and tourism industry, from the past until now, there is no strong historical relationship between Lei Yue Mun, local fishermen, and the Tin Hau Temple. In the old days, the residents of Lei Yue Mun were mainland immigrants, most of whom were Hakka. They worked as stonemasons and sustained themselves through vegetable planting and pig-farming. In the 1950 s, there were five quarry companies, including among others Wong Yin Quarry Company, Lei Hing Quarry Company and Tung Fong Quarry Company that operated their businesses along the hillside of the front sections of the Lei Yue Mun Tin Hau Temple.

Since 1951, the retreated troops of the Nationalist Party moved from Mount Davis to Tiu King Leng. Next to Lei Yue Mun village they established 'Ling Nam Sun Tsuen' (meant the South of Tiu King Leng) which was next to Lei Yue Mun village, and this resulted in an increase of population. Additionally, due to the Korean war, the United Nations imposed embargo on China which prompted smuggling activities. During the Korean War in 1950-1953, they were led by Fok Ying-Tung with the activities being conducted in Lei Yue Mun and Tuen Mun respectively. All the above helped to create a more prosperous 'Lei Yue Mun' but unfortunately it proved to be unsuccessful in the final count. Lei Yue Mun Tin Hau Temple, before and after its re-construction in 1953, witnessed certain historical transformations, but still the local development was very limited. One of the myths was the 'real' presence of Tin Hau which prompted the re-construction of the Tin Hau Temple. During the re-construction, people discovered a monument left by the pirate Cheng Lin-Cheong in the eighteenth year of the Qianlong reign period - exactly 200 years ago. That year, 1953 was also significant since many poets left numerous inscriptions on cliff surfaces.

Because of Lei Yue Mun's inaccessibility, the government had difficulties in maintaining law and order in the area. Some lawbreakers made use of the uncontrollable situation by serving heroin to the workers in the Taikoo Dockyard (Hung 2016: 19). Smoking and snorting heroin became the economic pillar in the region. In 1964, fishermen transported their fish catch to Lei Yue Mun for selling purposes. Initially they just sold the seafood from their small boats, so the workers of the Taikoo Dockyard would become their major customers (Idem 2015: 26-27). In 1967, the 'Hong Kong Riot' broke out. 
The government exerted stronger control on the use of gunpowder. Many quarry companies were unable to undergo mining so they gradually ceased operations. The economic development in Lei Yue Mun started to undergo transformations. Businessmen originally working in the quarrying industry turned to seafood industry and they also stared to promote the local tourism industry. Lei Yue Mun became popular for 'eating seafood'.

Lei Yue Mun of the 1950s was considered to be a place with no jurisdictions - without control neither on the part of the Chinese, nor British, nor Hong Kong authorities. In the 1960s, Lei Yue Mun slowly developed into a tourist spot. Smugglers, drug addicts and triad society members went there to eat seafood. Therefore, there was a saying that 'Cha Kwo Ling has licit/official temples, whereas Lei Yue Mun has illicit temples', which meant that there was a sharp contrast in the management of these two places. Today, in the Lei Yue Mun Tin Hau Temple most altar tables and altars are donated by the Ma's family of the Oriental Daily which was notorious for maintaining heroin industry.

The official name of the Cha Kwo Ling Tin Hau Temple was defined in honor of Lee Zhun for his outstanding contribution to eliminating piracy during the Qing dynasty and the temple was additionally provided a spirit tablet (also called a memorial tablet). Some people may be surprised by the origin of the official Tin Hau Temple in Cha Kwo Ling. But when Cheung Po-Tsai (the pirate) was offered amnesty and enlistment, the admiral Lee Zhun's troops were deployed in ‘Koon Tong Bay' (Kwun Tong Bay, 官璫灣). The spirit tablet of Lee Zhun (李隼) was already placed inside the Tin Hau Temple in Sai Tso Wan. Because of its relocation, such spirit tablet was placed in the temple in Cha Kwo Ling. On the other hand, since most people in Cha Kwo Ling work in the masonry industry, they treat 'Lo Pan' (魯班) as their patron saint and he is deified as God. The spirit tablet of Lo Pan was placed in the Cha Kwo Ling Tin Hau Temple so that people could also worship (Chan 1957: 23-24). Every year the Lo Pan Festival is celebrated with distribution of meals. In the past, it was done by the 'Hoi Tin restaurant'. But when the restaurant was closed, the local villagers and residents started to perform.

The transportation in Lei Yue Mun became more convenient with the emergence of bus route $14 \mathrm{C}$ in 1969. It was followed by the development of Yau Tong and Ko Chiu Road Estates. Due to the growth of population, Lei Yue Mun became a popular tourist destination. During that time, the areas around the Wine Bay (now Sam Ka Tuen 
Shelter of Lei Yue Mun) were crowded with new neighbors (new immigrants) who built chalets. The government also built temporary houses (Hung 2016: 22-23). All this contributed to the local economic development and made the economic activities more diversified in the Lei Yue Mun village. Factories, shipyards and ceramic activities were found in the village.

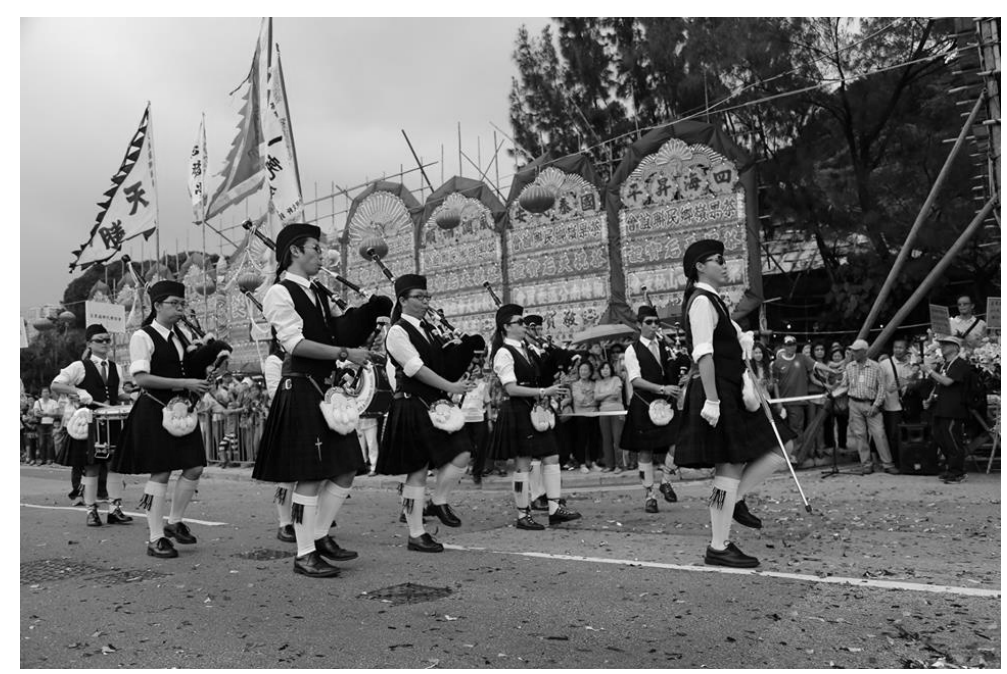

Fig. 5. The Tin Hau Festival in Cha Kwo Ling is well-respected by the community. People from all walks of life participate in this event

Source: author's photo

In the 1960s and 1970s, the economic situation in Cha Kwo Ling was more favorable than in Lei Yue Mu due to the economic differences between them. The arrangements for the grand event, Tin Hau Festival, were first initiated in Cha Kwo Ling Road (see Fig. 5). While Lei Yue Mun organized Tin Hau Festival celebrity event a month later. The original troupe in Cha Kwo Ling would also move to Lei Yue Mun to assist with its celebration. This is an example to illustrate the residents' helpfulness in Cha Kwo Ling. The local customs and practices in these two places also differ; the greatest difference consists in helpfulness and friendliness. Thus, people in Cha Kwo Ling established an extremely strong neighborhood relationship and always offer mutual support while in Lei Yue Mun this kind of neighourhood cannot be observed. 
In the 1980s, Hong Kong's economy started to take off. There started the development of industrial, commercial and financial enterprises while people were eager to enjoy high-end consumption. This increased the operating income of the seafood industry in Lei Yue Mun; besides, the richer and most competent elites in Lei Yue Mun were engaged in service industry, for example, they opened shops, and started to run their own business. But unfortunately, they focused just on their own benefits and lacked village sentiments. The situation worsened when the richer group moved out of Lei Yue Mun. A new group of immigrants came, but they were much poorer and they also lacked neighborhood helpful spirit.

One reason is that there had never been fishermen settlements in Lei Yue Mun. The owners running their seafood business did not work in the fishing industry before; they just changed from quarrying to the current job industry. Thanks to the International Seafood Festival which was held in 1992, Lei Yue Mun raised its reputation and became an international seafood tourist destination. Provided evidence shows that there is no linkage with the history of Tin Hau Temple. Today, the grand event 'Lei Yue Mun Tin Hau Festival' is organized by seafood restaurant owners. There is a change within the established relationship between the Tin Hau Temple and seafood industry. Lei Yue Mun Tin Hau Festival is held every year on the $23^{\text {rd }}$ day of the fourth month of the Chinese Lunar calendar.

Festivals in the villages are unforgettable. During the period of festival time people like to make comparisons. There was a saying 'Cha Kwo Ling is the elder brother, while Lei Yue Mun is the younger brother'. Other historical factors should also be taken into account in explaining this statement. First, people in Cha Kwo Ling discovered the production of kaolin. Second, the Asiatic Oil Company and the Cha Kwo Ling Main Street were situated there. Third, its economy was prosperous. Cha Kwo Ling used to hold the highest position among the 'Four Hills of Kowloon' in the past. Currently, only Cha Kwo Ling and Lei Yue Mun remain in the 'Four Hills of Kowloon' while two other villages were demolished. The celebration of Tin Hau Festival is prioritized in this way - Cha Kwo Ling celebrates it first, and then comes the turn of Lei Yue Mun.

According to historical data, Lei Yue Mun did not have its own celebration of Tin Hau Festival. Therefore, it was not necessary to hire a crew. Both Cha Kwo Ling and Lei Yue Mun employed the same troupe and Qilin team (麒麟隊, Chinese unicorn) for the festival (see 
Fig. 6). Actually, the scale of Lei Yue Mun Tin Hau Festival is very small, and it differs from the one in Cha Kwo Ling. There is also a sharp contrast in local manpower mobilization - Lei Yue Mun does not have enough manpower and it lacks the ability. The most remarkable thing in Lei Yue Mun is the existence of many seafood shops and restaurants. It is easier for them to raise funds for the performance of Tin Hau Festival. Unfortunately, the local elites just cooperate hypocritically, and they do not have mutual trust.

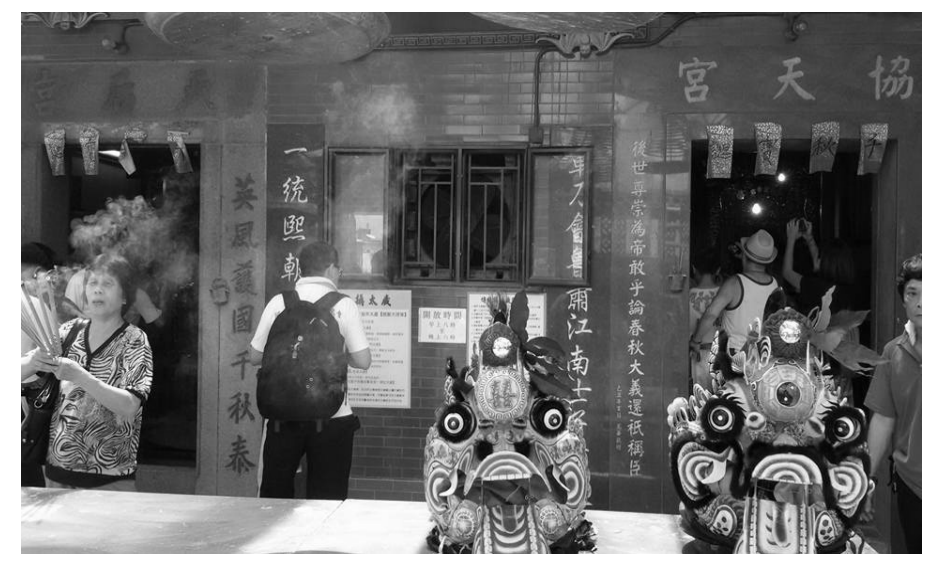

Fig. 6. Celebration of the Grand Tin Hau Festival - 'Qi-Lin' team performance from Cha Kwo Ling outside Lei Yue Mun Tin Hau Temple

Source: author's photo

Anyway, the most attractive and enjoyable part of the Tin Hau Festival is the 'Cantonese opera'. On the day of the event, both Cha Kwo Ling and Lei Yue Mun will unavoidably invite Tin Hau, the Goddess of the Sea, to watch a five-night and four-day Cantonese opera. When comparing these two places one can reveal some more differences. First, the bamboo theater in Cha Kwo Ling is much bigger than in Lei Yue Mun. Second, the seating capacity in Cha Kwo Ling is three times larger than in Lei Yue Mun. Third, the seats are fully occupied when the Cantonese opera show is on in Cha Kwo Ling, while Lei Yue Mun yields a different picture (see Fig. 7). Actually, the Leisure and Cultural Services Department (LCSD) is aware of such popularity in Cha Kwo Ling. It showed official recognition of their performance. Every year at the Tin Hau Festival, the department 
makes use of the bamboo theater. They additionally perform two-day 'Cantonese opera' when the official Tin Hau celebration ends.

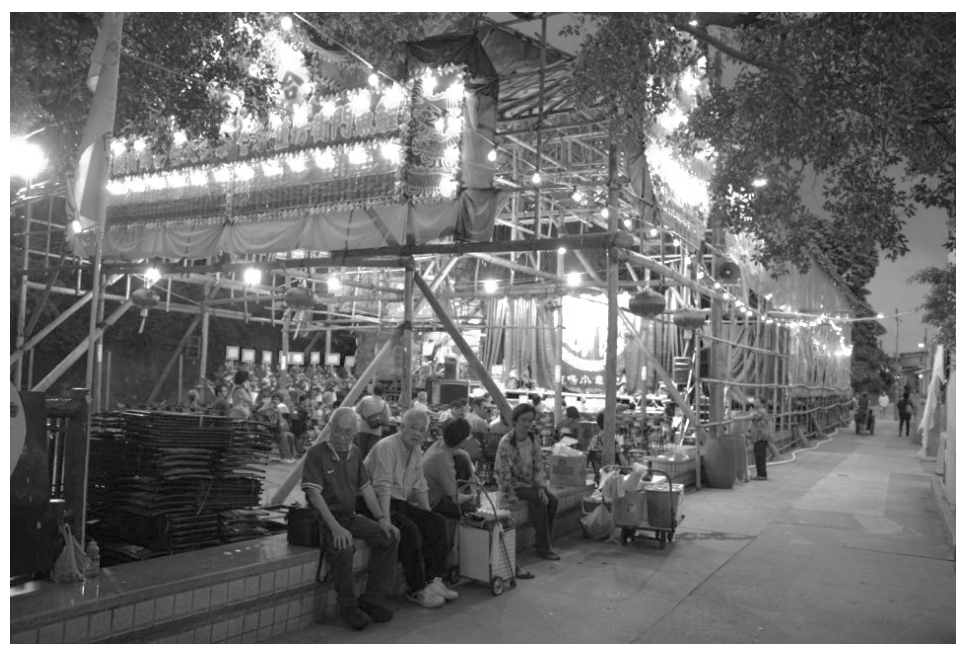

Fig. 7. The magic opera (with divine forces ${ }^{1}$ ) of the Lei Yue Mun Tin Hau Festival Source: author's photo

\section{CONCLUSION}

Hong Kong should be described merely by its economic development. Some places deteriorated and each community may have its own path of vicissitudes. Not only Cha Kwo Ling and Lei Yue Mun are geographically close, they also have a strong relationship with different paths of transformations. The Tin Hau Temples in both Cha Kwo Ling and Lei Yue Mun witnessed Hong Kong's historical development and transformations. The beliefs, customs and traditions of Tin Hau Temple and Tin Hau Festival were also passed down from generation to generation. Generally, in the eyes of local people, Hong Kong is stereotyped as a fishing village or it was falsely interpreted as a place of barren rock island with no houses built on it. But it is not true. The development and transformations of the two places help to provide an opposite historical picture.

Different transformations of the two territories were compared and we show that they have different paths of development. Though Cha Kwo Ling and Lei Yue Mun are geographically close, they have a strong networking relationship. They also used to have mutual cooperation and developments in the past, but the places themselves are 
quite different in their developments. It is especially obvious with respect to Hong Kong's situation - the developmental directions and paces of transformations of the two places are not the same. Actually, the origins of Tin Hau Temples and Tin Hau Festivals are not linked to fishermen very much in the two places. It was only through the developmental process that it related to the fishing industry, such as wholesale and retail fish, and seafood restaurants and tourism. Today, the villagers of Cha Kwo Ling are not connected with fishing industry, while Lei Yue Mun has successfully evolved to be a local leader in the seafood industry. It dominates the local resident's activity - the Tin Hau Festival. Although the economic development in Cha Kwo Ling cannot be compared with its golden days in the past, the inhabitants' sentiment and passion are still present. Therefore, many people actively take part in the Tin Hau Festival. At present Tin Hau Festival in Cha Kwo Ling is the largest-scale event in the region. Its spectacular occasion comes only second to the (same celebration) in Joss House Bay (Tai Miu Wan, 大廟灣) Tin Hau Old Temple.

Development is contingent. It is important to illustrate, or to explain the developments so the transformations of Cha Kwo Ling and Lei Yue Mun help to tell different stories from Hong Kong's history. The prosperity of Cha Kwo Ling relied on the nearby local developments. In the 1950s-1960s, it had oil depots, kaolin and quarry sites. There were also local fishermen and some additionally-built factories. All these provided superior economic circumstances. There were no adequate transportation facilities hence leading to remoteness. It is because of this isolation that the local region began to develop and achieved better results than other regions. After the war, many poor people (new immigrants) moved to Cha Kwo Ling. The economic developments slowed down or even deteriorated in Cha Kwo Ling in comparison with other regions due to the disappearance of superior economic situations. Cha Kwo Ling then became even poorer. But this did not hinder the villagers' sentiment. Many people, whether inside or outside the region, celebrate the Tin Hau Festival and now it is still a popular event. Outsiders can merely think about the internationalization of Hong Kong and prosperity of the city promoted by the British colonialization. Flourishing is not definitely achieved and different communities have their particular situations of development and changes.

The comparison of the economic development of the two places was made and there were revealed some differences. The economic 
development in Lei Yue Mun began at a later stage if compared with the development of Cha Kwo Ling. With the development of the seafood industry, many inhabitants became rich. But their richness prompted them to have living style incompatible with the traditional group. The local social mobility is quite limited. The residents' interest and participation in popular events is also low. Of course, it is difficult to compare the degree of prosperity with the past. The cultural inheritance of Lei Yue Mun is unfortunately gone and it is very different from the one in Cha Kwo Ling. There are also differences in villagers' sentiments. We have investigated the community building and found that the two places are remarkably different. The paper illustrates the exceptional narratives of transformation of different regions in Hong Kong, witnessing one place's flourishing and the other's deteriorating while people would only think about Hong Kong's developments in general. In addition, we also reveal the level of social harmonic situation in these two places and they serve as sharp comparisons and key differences.

\section{NOTE}

${ }^{1}$ Opera with divine powers is a form of Chinese opera played at religious ceremonies, at the opening of newly built temples, at miaohui, during taipingqingjiao, during ghosts and on the birthdays of gods and saints.

\section{REFERENCES}

Chan, Yam pang. 1957. Cha Kwo Ling. Hong Kong: The Department of Geography, University of Hong Kong.

Chan, Yuen ming Mary and Lee, Chun kau Paul. 2012. The Known, the Imagined, and the Recreating Lei Yue Mun Village. Hong Kong: University of Hong Kong.

Carroll, J. 2007. A Concise History of Hong Kong. Hong Kong: Hong Kong University Press.

Harbour and Hills. N. d. Business with Hong Kong. URL: https://www. harbourandhills.com/business-with-hongkong.aspx. Accessed 23.03.2020.

Hung, Chung fun Steven. 2015. Development and Transformation of the Cha Kwo Ling History. In Chan, Yat fong, and Chan Miu ling (eds.), Traveler. Vol. 25 (pp. 20-36). Hong Kong: Xianshan Academy. (In Chinese).

Hung, Chung fun Steven. 2016. The Unresolved Myth of Lei Yue Mun Sam Ka Cheun. In Chan, Yat fong, and Chan Miu ling (eds.), Traveler, Vol. 26 (pp. 15-24). Hong Kong: Xianshan Academy. (In Chinese). 
Hung, Chung fun Steven. 2017. The Place without Villagers History, Sai Tso Wan of Kwun tong Four Hills. In Chan, Yat fong, and Chan Miu ling (eds.), Traveler, Vol. 27, pp. 96-104. Hong Kong: Xianshan Academy. (In Chinese).

Kwok, Kam chu, Sun, Che Yung, and Wong, Tak Sang. 1987. The Study of Cha Kwo Ling Development. Hong Kong: Centre of Urban Studies and Urban Planning, Hong Kong University.

Lee, Hau pan. 2010. Lei Yue Mun: Rethinking Tourism Development. Hong Kong: University of Hong Kong.

Liu, Shuyong. 1997. An Outline History of Hong Kong. Beijing: Foreign Language Press.

Luk, Hung kay Bernard. 2005. Religion in Hong Kong History. In Lee Pui Tak (ed.), Colonial Hong Kong and Modern China: Interaction and Reintegration. Hong Kong: Hong Kong University Press.

Ng, Wai por. 1963. Cha Kwo Ling Kaolin Mine. Hong Kong: The Department of Geography, University of Hong Kong.

Tsang, S. 2004. A Modern History of Hong Kong. Hong Kong: Hong Kong University Press. 